\title{
THE ARTISTIC TEMPERAMENT AND THE ARTIST'S PROGRESS
}

\author{
By J. A. FULLER-MAITLAND
}

$\mathrm{T}$

HE popular idea of the artistic temperament, an idea fostered by most of the novels that take it as their subject, is that it is a kind of freak of nature, a more or less agreeabl e monstrosity; but while it is, perhaps fortunately, of rare occurrence in any family circle, it seems to be a perfectly natural and normal thing, which may be analysed with some benefit to the possessor or his friends. To be sure, it is impossible to detect its presence either at birth or during childhood; but many parents and guardians, when it begins to manifest itself, seem to lose their heads altogether, and to distract themselves with problems as to the treatment of the genius who has come so inopportunely into their midst. It is not really a calamity; but it is a good thing that it is not an everyday occurance for a genius to arrive in any ordinary family, and indeet, if it were so, the contemplation of a regular routine for its proper development, undertaken according to rules, would not be a very edifying one. We might suppose that a regimen of scales and hair-oil would be prescribed as the most practical preparation for the career of an infant prodigy; but the whole idea of such deliberate processes is repugnant to most people. No doubt in some families where one of the parents has shown outstanding artistic ability, there is a tendency to treat the children as if they were certain also to attain eminence in art. The artistic temperament is a most perverse thing, for it most seldom descends from parent to child without some change of kind; there are exceptional cases, like the family of the Bachs, for example, but it is far more common to find that where it is hereditary, the child is apt to show a preference for some other art than that in which his parents have achieved success. A painter's son will often turn into a musician, or a poet's into a painter, and these parents find themselves in the same quandary with the more commonplace parents who are faced with the difficulty I have alluded to.

To regard the temperament as abnormal, and to treat its owner as set apart from the rest of mankind, is to do great harm to a child, and not a little to the character of those who have to meet 
him on a basis of ordinary life. The isolation of one child from the rest of his brothers and sisters, on any account save physical or mental infirmity, is surely a very bad thing for all parties. We do not realize enough that on several sides the most eccentric genius is quite commonplace, or would be commonplace if his parents had only had the wisdom to treat him like others. Yet nothing is more common, whether in life or in novels, than to find the possessor of genius swayed by the same impulses as the rest of mankind; he is apt to be self-centred to a lamentable extent and in ordinary matters of business the same difficulties beset him that beset us who have no claim to genius. His faults, it is true, are apt to seem more glaring because they are found in a nature in which there is the divine spark of artistic accomplishment; but even after making all due allowance for this, there is no denying that the great majority of those who attain or strive for great positions in the world, are in the habit of exhibiting very undesirable defects of character on many sides. I cannot but think that this comes in a large measure from the exceptional treatment they receive in early days, when little or nothing is done to repress bad habits or inclinations, to encourage consideration for others, or to make reparation for the kind of everyday difficulties from which no genius can possibly be free. The average parent might really try to be a little more sensible than the hen who has hatched a duck's egg, and who watches with ever-renewed anxiety every effort of her foster-child to reach its natural element. Parents are perhaps deterred from treating an exceptional child in the same way as other children, in part by a natural anxiety that is identical with the hen's, and in part also by proud anticipation of the brilliant prospects they foresee for their offspring. Taking all things into consideration, perhaps the hen's point of view is not as foolish as it seems; the commoner fault in the present day, when the passession of genius is a solid asset in most people's opinion, is to try too hard to enforce the eccentricities of genius at every point, as though the hen were to try the experiment of attracting the young duck to the water by getting in herself, after the manner of the bathing-women at old-fashioned watering-places.

Whether the budding genius is an only child or has brothers and sisters to associate with, does not greatly affect the sense of loneliness which will most likely be felt by him through a great part of his life as his most constant experience. It is inevitable that the possession of certain unusual faculties and ideals should set him spiritually apart from companions who can look at a picture or hear music without emotion, while he is thrilling in every fibre 
to the call of great works of art that he cannot as yet comprehend. He can neither guess why he himself is affected, nor why his fellows can keep an even pulse when he is so excited. He will very soon learn to hide his dearest feelings in his own breast, and the discovery of some one who understands and sympathizes with him will be one of the great moments of his life. But, because this is so, it follows that the more regularly he can be treated like his companions in things that do not belong to his art, the greater will be his chance of growing up like other people, and the less will the spiritual isolation be felt. Granted that he can have some carefully conventionalized training apart from the study of. his special subject, he will be quite likely to obtain popularity among other young people, a popularity that will certainly be denied him if he is encouraged to keep himself apart from them in the ordinary circumstances of life. $\mathrm{He}$ will most probably be clever at games, and his fellows are extremely unlikely to "put nonsense into his head" or to make him think himself exceptional in any way. Isolation will be realized by him quite soon enough without parental care in encouraging the feeling by special treatment.

With regard to the difficult question of general education, those who have him in charge will almost certainly be puzzled to know how much of the technical study of his chosen art should be made to synchronize with other lessons. However great the genius, it is desirable that its owner should be sent into the world as well equipped as others with the kind of knowledge that most people take for granted; and it is very unusual, in the present day, to find even the most eccentric entirely ignorant of the rudiments of education beyond the "three R's." In this respect, a girl has less of a problem before her, for the ordinary curriculum of her studies will provide some opportunity for advancing in the arts of painting or music; but in the case of a boy, it is difficult to arrange for such special studies to be taken in addition to those which must be the groundwork of every one's education. The child of parents who are themselves distinguished in music or painting will certainly not suffer from any lack of opportunity of studying the art in which they excel; in certain classes of the social scale, he is far more likely to be overtrained, or even to end in the miserable career of a wonderchild, with its almost inevitable collapse of nerves or decline of artistic ability. Such remarks as these are not likely to have any effect whatever on those who are capable of exploiting a prodigy for their own advantage; it is the other type of parents who stand in most need of advice. 
In England, however it may be in other countries, the condition of education in this respect has so wonderfully changed for the better within the last half-century or so, that a boy who is clever at painting or music may safely be sent to most of the large schools, where he will find such technical instruction as will carry him on his artistic way and at least will certainly not hinder his progress. At most of the public schools, if not at all, a musical boy's studies are so arranged that he can get a certain number of hours, - not deducted from his playtime,-for his misical studies, besides the choral singing now so general, which, if it does nothing else, will help him to become a good reader; and he will be taught the rudiments of the instrument of his choice, in such a way that later masters will find little to undo. But there can be no harm in the artistic progress being slow during schooldays; after this period is finished, and the artistic training once definitely starter, we may fairly look for results much more quickly.

With the present abundance of institutions where music is the chief subject of study, it is most likely that a promising boy or girl, one in whom anything like the possession of genius may be hoped for, should be sent to one of these music-schools, rather than be taught at home. In this particular connection, there are very strong objections to a course of serious musical study pursued at home. First there is the difficulty and expense of getting teachers who are fully competent to deal with the different sides of music; some theoretical study must be taken as well as the instrument which demands prolonged technical exercise; and it is by no means every teacher who is capable of dealing with both the theoretical and the practical side of the instrumentalist's art. Still fewer are the singing-masters or mistresses who can even show their pupils the way to obtain some smattering of musical theory. There is also the danger, in home study, of the pupil not finding his level; his teacher will be quite unable to gauge his powers after a certain length of time, since all who have experience in this way know how difficult it is for a teacher to get outside his work in any given case, enough to judge what amount of real progress has been made by the learner. He will constantly be judging by the results of the last few lessons, and if the pupil happen to show a little more or less skill or animation than at the last lesson, he will be considered to have made some real advance or retrogression, when the difference may really depend upon the pupil's moods, or even on those of the teacher himself.

Every teacher knows how on some days pupils seem heavenborn geniuses, and on others are apparently qualifying for admission 
into a home for imbeciles; but few are willing to grant that the difference of mood may be quite as much in themselves as in those they teach. Such differences of mood are of course not unknown at the great music-schools, but their influence is to a great extent counteracted by the number of teachers under whom the studies are pursued, as well as by the system of examinations, at which experts, not immediately concerned with the regular training of the students, are asked to give an opinion as to their real progress. At the great music-schools, the budding genius will find himself in a new world, where artistic taste is no longer the exception but the rule, and where the things he most cares about, which he has been compelled to keep hidden from those about him, are the ordinary topics of conversation among his fellow-students. It will be a new delight to him to exchange ideas on his art with those who are in the came category with himself. Art, for a time, will for him descend from her shrine and take on the homely garb of daily life. The necessary drudgery, at this stage, will hardly be an unmixed delight, but after a short novitiate, the joy of occasional achievement will be felt to be the best reward for hours of technical labour, and on all sides doors will open into the hidden truths of art.

The period of study at one of our great music-schools is for most students a very happy one; the surroundings, so congenial to any one who has a real love of the art, the earnestness displayed by all in their work, and the opportunities of hearing the performances of other students, all make for enjoyment as well as profit. There is, it is true, a certain danger of a wrong ideal being set up, and what is called "professionalism" usurping the place of art. There must needs be present some of the sordid element of professionalism where everybody either belongs to the musical profession, or is anxious to enter it, and of course to make a living by it. A "professional" standard is all very well to maintain in the matter of technical accuracy, but the "professionalistic" view of life is sedulously to be avoided. It may be defined as the greedy seeking after fame or money as the main ends of the musical career, the setting-up of false standards of excellence, of prejudiced opinions, and the thwarting of all generous impulses. In the encouragement of this unpleasant trait, the teachers at a great school are quite as often to blame as anybody else; it is they who, in their self-satisfaction at their pupil's advance, fill her head with erroneous ideas of her own commercial value; "You sing," they will say, "quite as well as Mme. * * who gets twenty guineas every time she sings; therefore why should you not ask for the 
same terms?" The folly of this kind of suggestion is patent to every one who knows the musical world; even supposing the master's assertion to be correct, there are details in such things as a concert-manner, deportment, the habit of dealing with mankind, and a thousend things which Mme. ** possesses because she has been long before the public, but which the raw student, just emerging from the music-school, cannot hope to possess.

The pecuniary value of one's own services can only be ascertained after many months' experience of the public; here as elsewhere the only sound principle is to begin by asking the lowest terms that are possible without loss of prestige, and to work up slowly, as the public demand increases. The only people who do not see how foolish is the other system are the pupils and teachers at the schools; of course the one class takes the other's words as gospel, and the attempt to put them in practice ends in a disaster which outsiders cannot be blamed for thinking well-deserved. Professionalism shows itself, too, in the unreasoning admiration of everything that a fellow-pupil of the same institution may do, and an equally unreasoning censure of anything achieved by one who has studied elsewhere. This is a habit which is excusable, if not actually praiseworthy, among school-boys, but which, in artistic circles, both of painting and music, is to be regretted, and is sadly apt to last into maturity.

Another "professionialistic" prejudice that causes much misunderstanding, whether in the music-school or in connection with private tuition, is that it is treacherous to change one's teacher for whatever cause. At the music-school, such a change can only be effected after great searchings of heart, and difficulties of all kinds, and perhaps this is as it should be. But in the relations between a private pupil and his teacher, there is surely no reason for all the vexations, quarrels, and petty jealousies, that are engendered whenever the pupil, feeling that he has got from one master all that he can assimilate, makes the experiment of resorting to another for lessons. It is quite obvious, if we think of the thing without reference to individual cases, that no teacher can possess the knowledge and skill that are needed to make a pupil thoroughly proficient in the highest sense. If he were able to impart all that he himself knows of the art, even then the pupil would be but a pale copy of the master, and would probably lack all individuality. It is not necessary to undo one's whole method with every change of teacher, and it is the notion that this is compulsory which is the strongest argument used by those who protestagainst the practice of changing. Small differences of method 
do not greatly matter, particularly in relation to instrumental study. It is true that vocal students run a greater danger than others, for, while a pisnist who should destroy or damage his instrument by wrongly-directed practice can save up money to buy another, there is no known process of restoring an absolutely ruined voice such as are occasionally turned out even from the best music-schools in existence. Why should not eminent teachers recognize that the departure of a pupil throws no slur on the tuition he or she may have received, but is only due to the feeling that something in the course of study is unfitted for the special pupil?

A more liberal attitude towards the passage of pupils from one teacher to anothér would make for the happiness of teachers and pupils alike, would create a higher standard of final achievement, and would reassure the public as to the capacity of all the teachers; for at present, a master who complains of such transitions is generally suspected of not being quite such a good teacher as is supposed. Let it be frankly admitted that there is no such thing as a teacher who can teach every type of pupil, and there need be no ill-feeling between really competent masters. At the same time the world of music is full of quacks who do try to lure promising young singers (the danger is not so great with instrumentalists) away from their regular teachers; but the warnings against such as these would be easily and safely given, and would be believed by the pupil, if the free interchange of pupils were once agreed to amongst the competent teachers. There can hardly be an artist of any distinction who will say that he owes all he knows of his art to one single individual; the lives of all musicians and of all painters show that in youth they have been helped by various people, not always perhaps in actual lessons, but by the successive influences under which they have passed. The motives for such a change must of course be carefully scrutinized by the pupil and his friends before it is made; if it is an endeavour to follow in the steps of some friend who has done work with some other master, or a mere compliance with the dictates of fashion, a curiosity to try some patent "method," or the like, then it is well to hesitate before altering the method or course of study; but if the pupil is convinced that for him the method is mischievous, then the sooner he gets away from it the better.

Without going into the details of a bad method in each department of the executive art, it may be suggested that in any and all of them, bad method bears fruit in a feeling of fatigue after practising, in strained muscles, and in the deterioration in the 
quality of the tone of voice or instrument. If vocal practice causes sore throat or physical discomfort of any kind, if the pianist is encouraged to produce a tone which strikes his hearers as being harsh, then there is a fear that the method is faulty, and at this stage of the artist's development, physical ease should be striven after as if it were a thing in itself worth attaining. For a natural dissatisfaction with one's own rate of progress, a kind of musical "growing pain," a change of teacher is not always to be recommended; the student must pass through such stages of depression, and it must be the master's duty to spur him on through it to the next period of elation.

There is a characteristic of the artistic temperament in these early stages of development that often puzzles those who make a practice of observing it in progress. After the first few stages of technical work have been passed through, we generally find that the student's career consists of successive changes of idesl, almost like the swinging of a pendulum. Now the ideal of a perfect technique is set up and now this is again discarded in the effort to make music mean more, and in the desire to use technique as. a vehicle for making clear its inner message to the world. Henceforth, we may guess, technique and ideality will alternately attract the student, but ever as the pendulum swings to and fro, its oscillations will become shorter, until at last he arrives at the happy point at which he will deserve the name of artist.

His first longing for a power of deeper expression will perhaps show itself in a conviction of the insufficiency of technique alone to move the hearts of those who hear him; his taste and the old enthusiasm will combine to draw him towards some older artist who has found the secret of expression, and it is only too likely that at this next stage the technique he has acquired so labouriously may be a good deal impaired in the search for some shadowy ideal of emotionalism. As he tries his powers he will probably find that his growing want of accuracy is noticed by other people, and a revulsion will sooner or later take place, in which he will turn with renewed zest to the acquirement of a higher skill, such as may in time be subordinated to what he realizes as the end of all music, to interpret adequately the thoughts of the great compasers. At this stage he will bore his friends and relations with every sort of quack device for gaining great skill at little cost. This was the stage at which Schumann injured his hand so that-fortunately for the world-he had to give up the career of pianist for that of a composer, leaving the task of interpreting his music to his illustrious wife. All sorts of mechanical aids to 
muscular development, all the innumerable vocal methods, the various recipes for reviving the varnish of the old Italian painters or of the Cremonese violin-makers, belong to this stage. Such experiments, prompted by the natural revulsion from the formalism engendered by a too close devotion to technique for technique's sake, lead, in music, to such eccentricities as are typical of the ultra-modern composers, while in the art of painting it is charitable to suppose that the impulse which leads a certain school away from technical accomplishment of all kinds, is due to some such change of ideal.

With these, and such as these, the swings of the pendulum become ever more and more extended; but there are happily some in all the arts, whose pendulum-swings decrease in extent as they grow older, and these are they who attain to the perfect balance between technique and imagination which marks the true artist.

I have elsewhere called the successive stages of development by distinguishing names, such as the Student, the Amateur, the Virtuoso, and the Artist; and these names may serve as well as others to indicate the swings of the pendulum. For at the end of the student stage the kind of admiration of expression which is very apt to follow is also very apt to degenerate into an uncontrolled and hysterical kind of ardour which will in due course burn itself out; the second stage of struggling for an advanced technique generally has, for its immediate aim, the attainment of powers that will put especially difficult music within the performer's grasp, and will enable him to surpass his fellows in feats of manual dexterity. From this stage some never emerge at all; but most of those who do, reach next the final stage of their growth and become finished artistis; that is to say, they hold technique and expression at their true relative value; they will go through plenty of drudgery, for that must never stop through the whole career; but that drudgery will be almost unmixed pleasure as the necessary means to an end which is now kept well in view throughout, and this end, of interpreting the fairest thoughts of the most poetical minds to others, is among the highest that we can enjoy.

I do not for a moment mean to imply that all who deserve the name of artist have passed through exactly the stages of development that I have tried to describe, or have passed through them exactly in that order; but something like those stages may be perceived by those whose business it is to watch the careers of the applicants for artistic eminence. The watchers know, better than anyone else, how many of the promising candidates fall 
by the way, and how false is the picture drawn by some pessimists when they calculate the rate at which "finished" students are turned out of our great music-schools every year. "How is the world of music to maintain so many clever young people?" is a question we hear sometimes from those who are conscious of the impending dangers of overcrowding and foreign competition: But they forget the causes that thin the ranks before the higher places in the profession are reached. Some, unhappily, succumb to ill-health brought on by too much study or too little food; a certain number of the less highly-equipped have the sense to turn to some humdrum but more lucrative occupation in time, or definitely take up teaching and prepare themselves for the career of an instructor with that special intention. A few among the female students marry and are provided for by their husbands: and a good many fail from one cause or other to get hold of the public. When this is so, they and their friends are too readily tempted to cry aloud against professional jealousies, against intrigues, and to imagine all sorts of underhand methods which their rivals are employing to get themselves favourably noticed.

There is, I firmly believe, far less of this sort of thing going on than is commonly supposed; and, as a rule, the reason of failure is to be found in some radical defect in the performance. The first rule for obtaining success is to deserve it. Very often the obstacle is something only indirectly connected with art, some fault of temper or of education, some perverse idiosyncrasy which will secure a lasting unpopularity even for artists of high accomplishment. Dissipated habits are also to be reckoned among the hindrances to artistic success, and, closely allied to these, though less reprehensible, is the indolent attitude of mind that is sometimes begotten of one transient success. "If I can get money as easily as that, I need not trouble to regulate my expenses, and may relax my efforts to keep myself before the public eye." Such words as these have been the ruin of many a bright career. Often, too, some unlucky slip has been made at the beginning of public life; the young player or singer has perhaps fallen into the hands of an unscrupulous agent, and may have been induced to pay heavily for the chance of appearing at some reputable concert. To do this is morally wrong; but to be found out, and to get the reputation of having done it, means something very like ruin. It is extraordinary how soon little secrets of this sort do get out among the professional people who have anything to say to engaging artists. 
Numbers of young musicians do not see the great difference there is between the honest way of frankly sharing the cost of a concert with a colleague, and the dishonest way of paying surreptitiously for admission to the programme of a concert given by some eminent performer. In the latter case, it is hoped the audience will think that the concert-giver has already formed a favourable opinion of the aspirant's powers and that the association is a purely noncommercial one. In the former case, the giving of a concert by two or more people in conjunction will be recognized as a joint affair, and can deceive no one; this means of getting the ear of the public, though a little slower, is much surer than the way of paying a kind of illicit entrance-fee into the profession. Care must of course be taken, in entering upon such an association as is implied in the giving of a joint concert, that the other performer should be in an equal or superior position to one's own; this being so, it follows inevitably that the two are nearly always of about equal standing, since it is hardly to be expected that a really eminent artist will care to give a concert jointly with one who is unknown, unless the one is a pupil of the other, in which case, the older musician will probably have nothing to do with the risks or profits of the undertaking. In joint concerts of the kind I speak of, it is odd how seldom those who take the risks realize the great importance of contrast between the two performers. Many people see that there is a certain monotony of effect in a concert given by two men with a male accompanist, or by two women with a female accompanist, but beyond this they do not go. It is far more important to the general effect of the programme that the range of the two performers would be widely different; a soprano singer will make much more effect if her companion is a baritone than if he is a tenor, or with a violoncello as compared with a violin; a low contralto will be wise to join forces with a violin or a tenor singer, rather than with another voice or instrument of low range. Such details as this may seem very trivial, but it is details of this kind which very often make the difference between a decided success and a moderate one which is half a failure.

It may comfort some who are inclined to form too gloomy an opinion as to the stability of the musical profession, that in the course of a long experience of London concerts and music generally, I have never yet seen real talent ultimately and finally failing, unless there has been some very obvious cause, such as dissipation, carelessness about keeping engagements, or some noticeable fault of temper or character; many are the failures I have witnessed, but 
in every case there has been some very good reason for the unfavourable verdict of the public. The student may be spurred on to renewed efforts, during the anxious time when he is trying to get a footing, by reflecting that the English public is second to none in its loyalty to old favourites. The mere announcement of a veteran's name on a concert-programme is often enough to fill the concert-room, though he may have lost all real control of muscles or breath.

It is peculiarly unfortunate when, as sometimes happens, the obstacle to a successful career, one that is sometimes found insurmountable, is unmanageable nerves, which affect the performance to such an extent that the artist can never do himself justice. This question of nervousness is one that accompanies musicians all their lives through, for it is a mistake to suppose that the most proficient artists are altogether free from this drawback. Many of the greatest of all are so severely attacked by nervousness that each public appearance is for them a new ordeal. There is no doubt that some measure of nervousness is an inevitable accompaniment to real perfection of interpretation; but there is obviously a very great difference between the nervousness that strings up the faculties and increases the musician's vitality, and that which paralyses him and makes it impossible for him to reach even his own normal standard. A few distinguished musicians, but happily, only very few, have been obliged to give up the public exercise of their profession owing to this latter cause, and even they might quite possibly have been spared this necessity if they had known by what a very simple means the ordinary person can obtain control over his nerves. A few very deep breaths, in which the air is taken in and expelled as slowly as possible, will work a miraculous change in the whole nervous system, and will often enable a singer to steady his voice, or a player to feel that his fingers are not going to play him false.

With all its drawbacks, and they are not a few, the career of the finished artist is a delightful one, though it probably never reaches quite the giddy height of enjoyment that romancers are fond of painting. Of course, from the puritanical point of view, there are many and great temptations about the path of the young musician of either sex, and a certain number of promising musicians, as I have before hinted, give way to dissipation of various kinds; but as a general rule it may be asserted that the higher the artistic level gained, the higher will be the moral standard. To gain the highest place within one's own limitations, is only done by the constant exercise of will-power, independence, 
perseverance, as well as by keeping a high ideal in view. There is not much room left for the kinds of depravity to which the artistic temperament is peculiarly prone; to have reached the high planes of art the artist must have accustomed himself to resist temptations, and to deny himself many of the pleasures which are open to him. At the same time, it cannot be denied that the career of one who has not quite the energy or the ability to rise to that height of attainment which is possible for him, is beset with snares of many different kinds. Apart from ordinary dissipations, there are many sorts of inducements held out by unprincipled agents and others, which mostly result in the artistic undoing of the person who yields to them. The prostitution of great talents to the commercial interests of publishers is one of the most serious things in our musical life; but there are other roads to ruin that are, let us hope, of rarer occurrence.

The overcrowding of the musical profession led, some years ago, to various expedients for keeping a name before the public and so getting a spurious kind of fame. One of. these was especially strange, and would seem almost incredible were it not vouched for by a perfectly trustworthy person. A lady in the first years of her professional life, though not by any means a debutante, was called on by a soi-disant agent, who explained that he was ready (of course on receipt of a certain sum of money) to arrange for her sensational disappearance, with a disappointed public outside a concert-room, distracted speeches from the platform, baffled police, paragraphs in the evening papers, and all the rest of it; the advantage to the singer was to come in shape of a huge audience at her next appearance. Happily she realized that the kind of audience she might collect by such means was not the kind she would wish to enroll among her patrons, and that she must inevitably lose caste among the more respectable part of the public, so that she bowed the gentleman out of the house.

There are probably very few artists of any eminence who have not some stories to tell of similar ordeals through which they have had to pass, and those are wise who employ one of the more reputable agents to look after their affairs, and to guard them against the wiles of such people as I have described. That such ordeals strengthen the character, if they are resisted, is undoubtedly true, and the fact may perhaps account in some measure for the uprightness and nobility which is characteristic of some of the most illustrious of interpretative musicians. 